\title{
A ritualização do pertencimento
}

\section{O "paraiba" e seus espaços}

\author{
Fernando Cordeiro Barbosa*
}

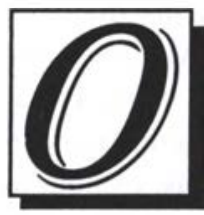

ato de migrar pressupõe o abandono do espaço social de origem, exigindo a procura não apenas por trabalho, mas também por moradia. A despeito de ser o trabalho a disposição central da migração, o onde morar e de que forma não se transcrevem como preocupações de menor importância. O trabalho e a residência para os migrantes, mais do que para os demais trabalhadores, têm uma estreita relação de dependência mútua (Sayad, 1992). Essa interdependência leva os trabalhadores a terem como uma das alternativas para a efetivação dos projetos intrínsecos à migração, a inserção em atividades produtivas que ofereçam a moradia (Barbosa, 2000). Não é por menos que as ocupações de empregada doméstica e de empregado de edifício são apontadas pelos estudiosos da migração, como Durham (1984) e Garcia Júnior (1989), como atividades potencialmente absorvedoras de mão-de-obra migrante.

Os trabalhadores aderem a essas ocupações por diferentes interesses, valores e agentes mediadores. Dentre esses motivos destacam-se o capital social propiciado pelas relações de parentesco e amizade, a desqualificação técnica para a execução de serviços que não se inscrevem em sua trajetória camponesa e certas similitudes com as relações existentes no espaço social de origem, como a pessoalização da relação de trabalho, bem como as estratégias adotadas por esses trabalhadores para a implementação dos projetos vislumbrados, como se bem traduz na articulação entre trabalho e residência. Não quero com isso dizer que todas as empregadas domésticas e todos os empregados de edifício sejam nordestinos e camponeses, e nem que todos que tenham essa trajetória se insiram nessas ocupações. Vale destacar, entretanto, que esses tipos de serviços constituem-se como alternativas de redimensionamento e integração de migrantes que estão diante de um processo de descampesinação'.

A inserção nessas ocupações que articulam casa e trabalho implica não apenas a constituição dos migrantes como trabalhadores, mas também como moradores. O "morar no trabalho", "morar em casa de família" e "morar no prédio", conforme os termos utilizados pelos entrevistados, conduz esses trabalhadores a serem moradores de espaços enobrecidos, como a Zona Sul do Rio de Janeiro, lugar esse habitualmente relacionado à camada média carioca. $O$ fato desses trabalhadores residirem nesses espaços tem suas implicações, como veremos a seguir, uma vez que o local de residência é simbolicamente investido de sentidos e valores, conforme pode ser percebido na literatura sobre espaços sociais de trabalhadores. 


\section{ESPAÇOS SOCIAIS DE TRABALHADORES}

A importância do local de residência e das relações de vizinhança têm recebido destaque nos estudos preocupados com a constituição da identidade e manifestações culturais da classe trabalhadora. O seu espaço social geralmente é apresentado como um sistema de referência, onde é desenvolvida uma ampla e particular forma de sociabilidade.

As análises recaem principalmente sobre segmentos da força de trabalho reproduzidos sob vínculos estabilizados, como o de trabalhadores que têm como pressuposto de projeto de vida a sua autonomia sobre a residência. Ou mesmo ainda daqueles cuja estabilidade do vínculo empregatício ocorre pela aceitação da perda relativa da autonomia pela moradia de favor.

O primeiro caso é foco de atenção dos estudiosos que privilegiam a construção da identidade do trabalhador a partir do local de residência, da vizinhança ou lazer. Os trabalhadores nesses estudos são vistos como construtores de bairros relativamente independentes. Esses espaços, nos centros urbanos, são denominados bairros operários, bairros populares, ou bairros periféricos e se configuram como áreas que são definidoras de um certo padrão de participação dos trabalhadores no contexto sócio-cultural.

Um bairro operário, segundo Macedo (1986), envolve uma população que se localiza e se apropria de áreas tidas como segregadas no espaço urbano, circunscrevendo o cotidiano dos trabalhadores a um mundo particular. Morar nesse espaço significa estar possuído de pontos de referência que lhes permitem negociar tanto a sua própria identidade de trabalhador (Guedes, 1997), como uma identidade social que possibilita a formação de associações políticas e culturais, como bem demonstra Zaluar (1985). Isto porque nesses espaços estão em seu "pedaço" (Magnani, 1998), lugar no qual o trabalhador está inserido numa particular rede de relações tecendo o seu cotidiano, onde reconhece e pode ser reconhecido em qualquer circunstância.

A articulação do espaço social com o cotidiano dos trabalhadores é também enfocada pelos estudiosos que analisam o sistema de relações em unidades de produção relativamente fechadas, como fazendas e fábricas. A posição do agregado em fazenda, analisada por Moura (1988), torna explícita a dependência pessoal pela morada, pois implica aceitação do desempenho do trabalhador às etiquetas fundadas num conjunto de regras interiorizadas nas relações existentes nessa unidade de produção.

A falta de estímulo à afiliação dos trabalhadores aos movimentos associativos, por terem a sua força de trabalho imobilizada, é apontada por Neves (1997) como uma das principais consequências da aceitação da perda relativa da autonomia pela moradia de favor ocorrida nas unidades de produção agro-industriais.Os operários das vilas operárias, estudados por Lopes (1988) e Alvim (1997), têm o espaço social e a existência controlados pela fábrica, em razão do papel que exerce sobre os trabalhadores ao disseminar e inculcar uma ideologia e uma moral do trabalho como estilo de vida.

Esses domínios sociais de existência da classe trabalhadora, apesar de assumirem características particulares em cada caso analisado, guardam entre si pontos comuns de relação, como o pertencimento dos trabalhadores a universos sociais que são construtores de referência em sua trajetória. A comparação entre o caso estudado, que é o de trabalhadores de origem migrante que vivem em espaços enobrecidos, com a família de casos similares, é um exercício fundamental, à medida que permite a compreensão da construção de modelos de organização social a partir do aprendizado do pertencimento.

O caso por mim operado enfoca a relação trabalhador e espaço social pelo estranhamento e perda relativa da autonomia. Esses pressupostos, diferentemente daqueles destacados nas análises sobre segmentos da força de trabalho que têm assegurado o imaginado inabalável pertencimento pela referência a um mundo social cujo tempo se espraia por gera- ções, visam demonstrar o aprendizado do pertencimento pela explicitação ritual do não-pertencimento.

Os migrantes de origem nordestina que se afiliaram às ocupações de empregada doméstica e empregado de edifício, em razão do oferecimento da residência, estão sujeitos aos códigos de um espaço que são tidos como concernentes a grupos sociais aos quais não fazem parte. Por estarem vinculados à residência, o lazer. o tempo, o espaço, a sociabilidade e os comportamentos desses trabalhadores sofrem interferência de normas sociais consideradas fundamentais para a vida familiar dos demais moradores. A condição de morador é subjugada pela condição de trabalhador. Através dessa condição, além da dependência e subordinação imposta, ocorrem hierarquizações e diferenciações sociais. Esses trabalhadores são, no espaço social onde vivem, moradores de segunda categoria, em razão das diferenças culturais entre os moradores que se constituem como trabalhadores e aqueles que se constituem como patrões.

\section{OS MORADORES DE SEGUNDA CATEGORIA}

Copacabana, Ipanema e Leblon, cartões postais do Rio de Janeiro, têm como população típica os moradores que apresentam signos próprios e distintivos de grupos sociais que ocupam posições privilegiadas em nossa estrutura social. Todavia, a composição social não varia apenas entre diferentes bairros da cidade, mas também, em parte, no interior do mesmo bairro ou área (Evers, Plantemberg e Spessart, 1985). A heterogeneidade de um bairro é decorrente da combinação de diferentes fatores, como: procedência, raça e classe social, que traçam linhas divisórias que podem ser invisíveis ou concretas.

A Zona Sul, independentemente de ser classificada e incorporada como local de classe média, apresenta uma sortida paisagem humana. Enquanto Copacabana é a encarnação do próprio cosmopolitismo, as favelas existentes 
nesses bairros nobres são um exemplo típico do marco concreto de distinção interna existente nesse espaço. Os habitantes dessas comunidades, todavia, não são classificados como moradores da Zona Sul, mas como pertencentes aos morros da Zona Sul - Pavão, Cantagalo, Chapéu Mangueira, etc.

Os bairros da Zona Sul do Rio de Janeiro têm também seus moradores invisíveis, desvelados apenas pela sensibilidade do olhar antropológico. Esses moradores invisíveis são as empregadas domésticas e empregados de edifício que residem no próprio trabalho. Os bairros residenciais de classe média geralmente demandam uma grande quantidade desses trabalhadores para viabilizar a funcionalidade dos edifícios e apartamentos da população típica desses locais. Apesar da condição de residência ser subjugada pelo trabalho, eles não deixam de ser moradores desses espaços, nem que seja na condição de subalternos, como moradores de segunda categoria.

Os próprios trabalhadores, ao comentarem, comparando-se com os demais trabalhadores, sobre as opções de inserção no espaço urbano, definem-se como moradores desses bairros. Ao contraporem a infra-estrutura desse local à precariedade e à violência dos espaços sociais dos demais trabalhadores, como as favelas e periferia urbana, valorizam a sua opção de trabalho e integração do contexto urbano, realizando uma hierarquização que os diferenciam em certos aspectos dos outros trabalhadores.

“A gente tem a desvantagem do salário, mas tem vantagem dos benefícios que a gente sempre tem. Comparando meu salário com o de outro trabalhador, você vai ver que a gente ganha mal, mas tem mais vantagem... O cara mora mal, mora no subúrbio, mora com medo dos bandidos matar ele. Tem que pegar condução. Paga moradia, paga luz, paga água, paga energia, $e$ eu não. Moro aqui na Zona Sul, moro bem... Não pago água, energia, não dependo de ônibus pra ir pro trabalho. Já moro no trabalho. A gente tem essa vantagem. Pode ir à praia. A praia é aqui pertinho. Tando aqui na Zona Sul é bem mais fácil." (I., 27 anos, nascido em Campina Grande/PB, migrou para o Rio de Janeiro em 1993 e trabalha como auxiliar de portaria em Ipanema).

Ao mesmo tempo que a condição de morador de bairros enobrecidos os distinguem dos demais trabalhadores, a posição de subalterno não possibilita uma relação horizontalizada com os outros moradores desse espaço. A vizinhança nesse caso não funciona como um espelho (Sarti, 1996). A interação com os moradores do bairro, diferentemente do que acontece nos "bairros populares", não funciona como uma malha de relações que possibilita a troca de informações, idéias e o estabelecimento de um pequeno sistema de empréstimo e ajuda, conforme pode ser visto nos estudos de Macedo (1986) e Magnani (1998).

Apesar de moradores, consideram-se e são classificados como porteiros ou empregadas domésticas. A posição de subalternidade é demarcada em todo esse espaço, havendo lugares onde não transitam, como certos restaurantes e lojas. Mesmo em ambientes comuns a ambos, como supermercados, padarias, farmácias e bares, ocorrem diferenciações e demarcação de convivência.

Essa distinção é fruto de um sistema social que tem como lógica de funcionamento homologias e oposições (Bourdieu, 1992). Os estilos de vida de cada grupo social imprimem desvios diferenciais que acabam por denunciar a posição que cada um ocupa na estrutura social. Os sinais de diferença, todavia, não se limitam à mecânica concreta do sistema de produção, mas se redimensionam em outras formas de dominação e hierarquização social. O regionalismo expresso nas oposições sudeste/nordeste e rural/urbano, também são responsáveis por ações simbólicas que contribuem para a distinção e hierarquização. $\mathrm{O}$ sotaque nordestino, a linguagem camponesa, a maneira de andar e o estilo de vestir e de se enfeitar desses trabalhadores - os "paraíbas" como são preconceituosamente denomi- nados os migrantes nordestinos no Rio de Janeiro, apresentam-se como manifestações exteriores que exprimem a sua posição de subalternos, reforçando a discriminação existente, não apenas nesses espaços enobrecidos, como em toda a sociedade.

A relação desses moradores de segunda categoria com o espaço social onde vivem se faz por maı os concretos e simbólicos de inclusão e exclusão. Se a condição de subalternos os excluem de certas referências desse espaço. inviabilizando a sua inserção em pontos de sociabilidade dos moradores privilegiados, essa mesma posição de morador de segunda categoria leva os trabalhadores a (re)criar códigos e espaços onde possam firmar e (re)construir sua identidade, colocando em jogo suas múltiplas e complexas referências.

Os modos de sociabilidade, as formas de lazer e as manifestações culturais da classe trabalhadora são associadas geralmente a uma identidade comum e a um estilo de vida próprio que são responsáveis por um todo coerente e unitário. Todavia, os estoques simbólicos e culturais desses segmentos de trabalhadores, apresentam-se como um conjunto fragmentário que se alimenta da articulação de diferentes contextos, situações e universos sociais. Antigas tradições do mundo rural e novas identidades adquiridas na sociedade urbana encontram-se entrelaçadas no cotidiano desses trabaIhadores. Por seu turno, a condição de morador de um espaço enobrecido, mesmo que na condição de subalterno, implica a articulação de informações e valores culturais de outros grupos sociais que também são responsáveis pela produção e consumo de múltiplas manifestações culturais.

A condição de morador da Zona Sul proporciona a esses trabalhadores gozarem do lazer predileto dos cariocas que é a praia. A caminhada pela orla, o banho de mar, o jogo de futebol e a conversa na areia são apresentados como um dos principais desfrutes desse espaço enobrecido. A praia, local amplo onde podem acontecer aproximações entre iguais, re- 
presenta a valorização de sua escolha de inserção no sistema produtivo, pois ela permite que estejam em um lugar idealizado, tanto por eles, como por demais segmentos da classe trabalhadora e da sociedade.

Outros ambientes de lazer valorizados por esses trabalhadores nesses espaços enobrecidos, são os cinemas, os shopping centers e mesmo espetáculos populares e gratuitos que acontecem na praia ou parques. O caminhar pelo bairro, reconhecendo suas ruas e praças, prestando atenção nas lojas, pesquisando preços e admirando novidades de consumo, transcrevem-se também como atividades de descontração e divertimento. A facilidade de acesso a essas formas de lazer, conduz, inevitavelmente, à comparação de sua condição com a dos demais trabalhadores, especialmente daqueles, muitas vezes seus parentes e amigos, que residem na periferia urbana.

Estarem perto desses lugares pode significar também a aproximação com valores de um grupo social ao qual não pertencem e o distanciamento de manifestações culturais mais corriqueiras dos trabalhadores que moram em bairros populares. Entretanto, se é incontestável que esses trabalhadores passaram a usufruir de certos tipos de lazer e sociabilidade pertencentes ao cotidiano de uma camada social privilegiada, é necessário registrar que essa apropriação ocorre apenas aonde é possível, cultural e economicamente, e é feita até certo ponto e até certo grau, sendo realizada ainda com estilo e característica própria.

Por seu turno, as empregadas domésticas e empregados de edifício, como não poderia deixar de ser, também se identificam como trabalhadores e com esses realizam preferencialmente suas formas de sociabilidade. Os seus companheiros de espaço social são os colegas de trabalho, como porteiros de prédio vizinho, outras empregadas e trabalhadores que realizam serviços nesse espaço social, como carteiros, garçons, vendedores e balconistas. A sociabilidade entre eles ocorre nos bares, nas praças, na praia, nos próprios locais de trabalho, como na portaria, e nas lojas e supermercados.
Para dar forma a modos de sociabilidade particulares, apropriam-se de certas porções desses espaços enobrecidos. O território do seu cotidiano é demarcado por pontos de convivência. Nesses locais esses trabalhadores, cercados por paredes reais ou imaginárias, podem se exibir e colocar em jogo suas identidades.

Elegem, inclusive, lugares onde realizam a reafirmação de sua condição de migrante nordestino. Esses locais, como a Praça Serzedelo Corrêa, em Copacabana, permitem a construção de diferenciações e servem como ponto de encontro de conterrâneos, onde podem ficar mais a vontade entre iguais. Nesses espaços trocam informações sobre o local de origem, enamoram-se e reencontram parentes e amigos.

Os bares também são espaços privilegiados de convivência desses trabalhadores. Existem bares nesses bairros enobrecidos, onde esses moradores invisiveis, juntamente com outros trabalhadores, criam marcas de identidade. Ali, entre iguais, acompanhados de cerveja ou cachaça, ouvindo música, assistindo jogos de futebol ou namorando, praticam exercícios de reconhecimento e pertencimento, como bem traduz a música $O$ rancho da goiabada de João Bosco e Aldir Blanc:

(...) $O$ bar

Onde tantos iguais se reúnem e

contando mentiras

Pra poder suportar..

Ai, são pais-de-santo, paus-de-arara, são passistas,

São flagelados, são pingentes,

balconistas,

Palhaços, marcianos, canibais,

lírios pirados,

Dançando, dormindo de olhos abertos à sombra

Da alegoria dos faraós embalsamados.

\section{* Fernando Cordeiro Barbosa é mestre em} Antropologia pelo Programa de Pós-Graduação em Antropologia e Ciência Política da $U F F$.

\section{NOTA}

1. Segundo informação de dirigentes sindicais dessas duas categorias profissionais, a mão- de-obra na ocupação de empregado de edifício no município do Rio de Janeiro é constituida basicamente por trabalhadores de origem nordestina, enquanto que entre as empregadas domésticas há uma heterogeneidade quanto à naturalidade das mesmas, existindo trabalhadoras tanto dos estados do Nordeste, como de Minas Gerias e do interior fluminense ou mesmo da capital.

\section{REFERÊNCIAS BIBLIOGRÁFICAS}

\section{ALVIM, Rosilene}

(1997) A sedução da cidade: os operários. camponeses e a fábrica dos Lundgren. Rio de Janeiro, Graphia.

BARBOSA, Fernando Cordeiro

(2000) Trabalho e residência: Um estudo das ocupaçōes de empregada doméstica $e$ empregado de edifício a partir de migrantes "nordestinos". Niterói, EDUFF.

BOURDIEU, $P$.

(1992) A economia das trocas simbólicas. Sâo Paulo, Perspectiva.

DURHAM, Eunice $\mathrm{R}$.

(1984) A caminho da cidade: a vida rural e a migração para São Paulo. São Paulo. Perspectiva.

EVERS, Tilman; MULLER-PLANTENBERG, Clarita e SPESSART, Stefanie

(1985) "Movimentos de Bairro e Estado: Lutas na esfera da reprodução na América Latina" Cidade, Povo e Poder. Rio de Janeiro, Paz e Terra.

GARCIA Jr., Afrânio R.

(1989) O sul -Caminho do Roçado: estratégias de reprodução camponesa e transformação social. Rio de Janeiro, Marco Zero: Brasilia, Editora Universidade de Brasilia, MCT-CNPQ.

GUEDES, Simoni Lahud

(1997) Jogo de corpo: um estudo de construção social de trabalhadores. Niterói, EDUFF.

LOPES, José Sérgio Leite

(1988) A tecelagem dos conflitos de classe na cidade das chaminés. Rio de Janeiro, Marco Zero; Brasília, Editora da UnB.

MACEDO, Carmen Cinira

(1986) A reprodução da desigualdade. São Paulo, Vértice.

MAGNANI, José Guilherme Cantor

(1998) Festa do pedaço: festa popular e lazer na cidade. São Paulo, Brasiliense.

MOURA, Margarida Maria

(1988) Os deserdados da terra. Rio de Janeiro, Editora Bertrand Brasil.

NEVES, Delma Pessanha

(1997) Os fornecedores de cana e o Estado intervencionista. Niterói, EDUFF.

SARTI, Cynthia Andersen

(1996) A familia como espelho: um estudo sobre a moral dos pobres. Campinas, Autores Associados.

SAYAD, Abdelmarlek

(1992) L'immigration ou Les paradoxes de l'altérité. Bruxelas, De Boeck Université.

ZALUAR, Alba

(1985) A máquina e a revolta: as organizaçōes populares e o significado da pobreza. São Paulo. Brasiliense. 